\title{
A EFICÁCIA DO ACESSO À JUSTIÇA POR MEIO DA ANÁLISE ESTATÍSTICA DOS JUIZADOS ESPECIAIS CÍVEIS DO ESTADO DO RIO DE JANEIRO
}

\section{Luciane Mara Correa Gomes ${ }^{1}$}

\section{Resumo:}

O juizado especial cível pode ser para muitos a única via de acesso à justiça, seja por não requisitar o recolhimento inicial de custas judiciais, seja pela baixa complexidade das demandas, porém passou a enfrentar a problemática do volume de demandas. O elevado número de ações distribuídas tem sido a justificativa para a justiça morosa, sem considerar outros fatores de suma importância. O presente trabalho avaliará os dados estatísticos do tribunal, confrontando-os com o quantitativo de recursos humanos para apurar os entraves de eficácia. A metodologia aplicada será qualitativa, pautada em jurimetria, utilizando ainda método bibliográfico.

Palavras-chave: Acesso à justiça; Tribunal de Justiça do Estado do Rio de Janeiro; morosidade processual; recursos humanos; jurimetria.

\section{THE EFFECTIVENESS OF ACCESS TO JUSTICE THROUGH A STATISTICAL ANALYSIS OF SMALL CLAIMS COURTS OF THE STATE OF RIO DE JANEIRO}

\begin{abstract}
Small Claims Court may be for many the only way to access justice, either because it does not require the initial payment of court fees, or because of the low complexity of the lawsuits, but it began to face the problem of the lawsuits volume. The high number of distributed lawsuits has been justification for sluggish justice, without considering other factors of utmost importance. This work will evaluate court's statistical data, comparing it with the quantity of human resources in order to determine to efficiency obstacles. Methodology applied will be qualitative, based on jurimetrics, and also using bibliographical method.

Keywords: Access to justice; Court of Justice of the State of Rio de Janeiro; procedural delays; human resources; jurismetry.
\end{abstract}

\section{INTRODUÇÃO}

Com o advento da conscientização das sociedades acerca de seus direitos, garantias e liberdades, o Poder Judiciário deparou-se com indivíduos mais ativos quanto à busca pelos direitos e os meios processuais para constituí-los. Todavia, ante a este movimento, não houve

\footnotetext{
${ }^{1}$ Mestre em Direito Público e Evolução Social pela Universidade Estácio de Sá. Bacharel em Ciências Jurídicas e Ciências Sociais pela Universidade Federal do Rio de Janeiro. Integrante do Colégio de Professores da Academia Brasileira de Direito Constitucional. Endereço eletronico: lucianemara@ uol.com.br. Acesso currículo Plataforma Lattes: http://lattes.cnpq.br/7142619530244859
} 
a adequada preparação do campo judiciário com vias a recepcionar o aumento no volume de demandas, decorrente de litígios de baixa complexidade, advindos das dinâmicas de conscientização da população dos direitos conquistados, com isto denotando desigualdade no acesso à justiça.

Em uma tentativa de suprimir os efeitos desta morosidade, para atender àquelas ações, criou-se o juizado especial cível como inovação e que surtiu resultados positivos por algum tempo, uma vez que, face à baixa complexidade dos litígios, havia velocidade no atendimento deste serviço público judicial. É necessário apontar que, com o constante crescimento do número de demandas pendentes, sem a adequação do campo judiciário para atender cada vez mais ao crescente volume de demandas, o juizado especial cível também começou a apresentar o problema da morosidade.

Diante do quadro apontado de lentidão na entrega da prestação jurisdicional ou do bem da vida pretendido, o campo judiciário volta ao ponto anterior que antecedia a existência dos juizados especiais cíveis, pois este quadro de morosidade torna prejudicial ao acesso à justiça, que é mais sentida no grupamento social em situação de hipossuficiência, pois há dependência do regular funcionamento dos juizados especiais cíveis para possa usufruir de uma prestação jurisdicional justa, uma vez que, pelo fato de não haver a exigibilidade de recolhimento das custas processuais na distribuição da demanda, é um dos maiores atrativos para o ajuizamento de ações em sede de juizados especiais.

A problemática desta pesquisa está concentrada em apontar os fatores que culminam na ineficácia dos juizados especiais cíveis pela demora na entrega da prestação jurisdicional. Com o objetivo de identificar as causas desta morosidade, avaliando o quantitativo de demandas e o quadro de servidores e de juízes que atuam na esfera dos juizados, analisando o tempo médio de tramitação de ações nesta esfera.

O trabalho que aqui se propõe adota metodologia qualitativa, pelo método de jurimetria e de revisão bibliográfica, tomando como base de dados, a publicação Justiça em Números com as estatísticas do ano de 2020.

\section{A ESTRUTURA dO JUIZAdo ESPECIAL CÍVEL E SUA CONCEPÇÃo TEÓRICA COMO DIREITO FUNDAMENTAL}


A evolução do acesso à justiça no Brasil deve ser avaliada a partir das considerações tecidas por Paulo Cezar Pinheiro Carneiro (2000) quando observa as anomalias do acesso ao poder judiciário e da prestação jurisdicional eficaz. Para o autor, o fenômeno da carência da sociedade deste acesso deve ser suprido pelo poder judiciário, quando há a busca pela solução de conflitos por meio de um acesso à justiça, sendo este alcance assegurado a todas as camadas da sociedade. O questionamento que surge é de que modo poderá haver a atenção às necessidades do homem mediano por meio da prestação jurisdicional célere.

A princípio, deve ser estabelecido que o acesso à justiça deva ser igual e eficiente e democratize o conceito de efetividade de direitos individuais. Assim, a partir desta premissa, a implantação dos juizados especiais cíveis garante não só a resolução de causas de pequeno valor, mas também o exercício da cidadania, já que tais garantias englobam os valores de referencial como gratuidade, rapidez, desburocratização, informalidade, equidade e efetividade.

A implantação dos juizados especiais cíveis teve como objetivos o desafogamento da justiça tradicional e a capacitação de grupos vulneráveis a demandar de modo satisfatório às suas necessidades. Em outras palavras, a obtenção do serviço público judicial acessível e que deve ser entendido como aquele que é útil, proporcional e operacional. Na prática, a união destes três princípios é que possibilita o desenvolvimento do papel institucional do poder judiciário. $\mathrm{O}$ acesso democrático da população ao poder judiciário não se basta apenas pela conscientização da sociedade acerca de direitos, mas também que possa haver a solução de conflitos no âmbito judicial sem nenhum obstáculo, sob pena de centralizar o acesso a um determinado grupo ou classe.

Não restam dúvidas a respeito da fundamentalidade do direito de acesso à prestação jurisdicional célere, eficaz e tempestiva, face à sua inserção no artigo $5^{\circ}$ da Constituição de 1988. Noutra volta, o distanciamento havido entre a sua eficiência e o atual estado de morosidade dos tribunais brasileiros tem ocupado lugar de destaque nas pesquisas e trabalhos desenvolvidos nas academias e está não só na pauta dos debates legislativos para as reformas processuais ocorridas, como também das regulamentações do Conselho Nacional de Justiça (CNJ).

Importante recordar que a grande parte das reformas processuais do último quarto do século passado não conseguiu conferir ao Poder Judiciário uma zona de conforto para decidir 
e solucionar conflitos entre os indivíduos, num prazo mínimo, suficiente a satisfazer aquela necessidade do indivíduo alcançar o bem da vida no menor lapso temporal. Esta necessidade tem sido o alvo das recentes resoluções do Conselho Nacional de Justiça, em especial, aquelas destinadas à desmaterialização dos processos e a realização de atos processuais e préprocessuais por meio virtual, como também o atendimento das serventias.

Sob a chancela de ter sido a grande responsável pelo assoberbamento dos tribunais, a explosão de litigiosidade tem sido tratada como a principal culpada pela demora na entrega da prestação jurisdicional e prejudicial ao acesso à justiça. É importante identificar no conceito de acesso à justiça, compreendido como garantia de direito formal do indivíduo, esta competência pertence ao Estado, já que ele figura como detentor do monopólio da jurisdição, sendo de sua responsabilidade o fornecimento dos meios eficientes para recompor a violação dos direitos. Entretanto, não é só o fornecimento de meios eficientes, cabe ainda oferecer condições igualitárias para o acesso. A certeza do direito pelos cidadãos não é suficiente para garantir a justiça, é imprescindível que haja igualdade dos cidadãos perante a lei (CALAMANDREI, 2004).

Possibilitar e facilitar o acesso à justiça foi e tem sido uma preocupação constante nas sociedades modernas, principalmente após o reconhecimento da sua posição de direito fundamental e de direitos humanos. Como objeto de estudo de Mauro Cappelletti e Bryant (1988) o acesso à justiça é composto por três vertentes no que se diz respeito à igualdade de armas: o acesso pela coletivização de direitos; a construção de métodos alternativos para decidir causas judiciais e a instrumentalização do acesso a quem não possua condições técnicas e financeiras para a litigância.

Os dois eixos fundamentais para a construção desta pesquisa devem ser delimitados como sendo o custo do litígio e a sobrecarga dos tribunais. O entendimento da satisfação das partes envolvidas em um litígio se operacionaliza quando alcança celeremente o resultado da demanda (CAPPELLETTI, GARTH, 1988). Por custo do litígio deve-se compreender também a obtenção de meios para redução do congestionamento do judiciário, conferindo resultados efetivos para a demanda, já que o volume de processos represados nas serventias obstaculariza a celeridade na resposta estatal face à redistribuição deste acervo para o quadro de recursos humanos do campo judiciário. 
Esta afirmação encontra respaldo nos apontamentos deduzidos por Boaventura de Souza Santos (2007), que indicou diversas saídas para a sobrecarga dos tribunais, todas com relacionadas diretamente com o tempo nos processos. Para o autor, o tempo de espera repercute no indivíduo que busca o tribunal para resolver seu problema o sentimento de desconfiança na eficácia da justiça. $\mathrm{O}$ autor ressalta ainda que a informalização da justiça, reapetrechamento dos tribunais com recursos humanos e infraestruturas, automatização, novas tecnologias de comunicação e informação, criação de tribunais especiais para a pequena litigação de massa e reformas processuais são medidas que podem diminuir o acervo processual e reduzir a morosidade judiciária.

Neste ponto, cumpre apontar que a morosidade é prejudicial não só para as partes interessadas, como também para a qualidade no funcionamento dos tribunais. Não é plausível aceitar que o excesso de burocracia, o positivismo e o legalismo devam ser adotados com vias a eliminar a sobrecarga de trabalho no campo judiciário. Pelo contrário, tais condutas gerarão efeitos nefastos ao jurisdicionado e não traduzem o conceito de justiça cidadã.

Manter o exercício da satisfação da pretensão a ser recebida do Estado, seja qualitativa, seja quantitativa e é, para o indivíduo, algo valorativo. O campo judiciário deve ter condições estruturais para recepcionar, sem qualquer comprometimento do serviço público judiciário, o volume de ações inerentes às novas exigências constitucionais e processuais com o resultado prático satisfatório para todos os interessados. A falha neste resultado acarretará para o poder judiciário, consequências danosas, afetando a funcionalidade da máquina judiciária, sob pena de sofrer mudanças desintegradoras. Esta posição é assumida por Aurélio Wander Bastos (2001) ao fazer a abordagem da estrutura interna da administração da justiça, sintetizando que cabe a máquina administrativa do Judiciário efetuar levantamentos, promover aprendizados e adaptar aos novos padrões de comportamento, alterando aqueles que interfiram na sua avaria.

Assim, cabe ao Estado identificar dinâmicas que cumpram esta garantia fundamental, conferindo as garantias processuais, mesmo que o campo judiciário continue a receber cada vez mais um volume maior de demandas. É necessário equilibrar o recebimento deste volume, fazendo o regular desenvolvimento destas ações, ainda que não possua a estrutura adequada para atender a sobrecarga de processos distribuídos e pendentes o tratamento apropriado. 
Não é forçoso assegurar que, dentre os diversos movimentos havidos, a reforma da legislação processual tem sido a preocupação mais pontual, mas não significa afirmar que a razoável duração do processo possa ser definida como aquela entregue no menor tempo possível. Não obstante seu conceito aberto, é, a partir da jurisprudência da Corte Europeia de Direitos Humanos, que se encontra alguns critérios identificadores do que se pode chamar de razoável: a complexidade da causa; o comportamento das partes e o comportamento do juiz na condução do processo, são os principais aspectos do que seja razoabilidade de tempo para processar, julgar e satisfazer o indivíduo.

O que torna imperioso identificar é se a resposta entregue pelos juizados especiais cíveis é mais célere e mais eficiente, além de preservar a proteção constitucional das garantias processuais fundamentais. É oportuno apontar que os agentes envolvidos no processo devem ser participativos, pois é um estado de concretização da democracia participativa na tomada de decisões. Nesta linha de raciocínio, cabe trazer o posicionamento de Humberto Dalla Bernardina de Pinho (2015) ao afirmar que tanto o direito material quanto o direito processual não podem deixar de atender aos anseios sociais, sem perder sua essência, pois o acesso à justiça está compreendido na ordem civil constitucional, com o fim de assegurar a devida proteção as grandes carências e necessidades da sociedade de massa. Em apertada síntese, a colaboração das partes no resultado do processo deve ser vista como um princípio processual e como componente da participação democrática do indivíduo no conflito social.

Para garantir a ordem jurídica justa, o poder judiciário deve assegurar aos jurisdicionados não a eficiência da solução, mas também um resultado mais rápido para o conflito. Diante desta urgência, Paulo Cesar Pinheiro Carneiro (2007), em pesquisa institucional realizada pela Universidade do Estado do Rio de Janeiro e a Universidade Estácio de Sá, asseverou que quatro princípios devem nortear a decisão proferida pelo campo judiciário. São eles: a acessibilidade, a operosidade, a utilidade e a proporcionalidade. Por acessibilidade, compreende-se como a etapa que assegura a qualquer cidadão o instrumento eficaz para estar em juízo e ainda que opte por outro que não seja excluída a prestação jurisdicional. Por operosidade, a atuação ética daqueles que atuam no campo judiciário; a utilidade, com o fim de promover a entrega do bem da vida almejado de forma rápida sem sacrifícios exorbitantes ao vencido e a proporcionalidade que privilegia o interesse mais precioso e que satisfaça a uma gama maior de pessoas. 
Neste sentido, para que a satisfação do indivíduo seja atingida, o poder judiciário deve adotar métodos eficazes para que não ocorram retardamentos ou etapas protelatórias, como o caso de audiências conciliatórias infrutíferas sem a devida orientação das partes. Leonardo Greco (2015) preconiza que os cidadãos se sintam seguros de que a justiça estatal estará sempre de portas abertas para coibir os abusos ou erros manifestos que ocorrem na sua atuação.

Nesse ponto, o trabalho se ocupa em avaliar o que seria uma duração razoável ou estabelecer o que seria tolerável aceitar, como meio a compelir a "fuga da justiça", para aferir a eficiência do acesso à justiça. Isto por que o fenômeno da lentidão afeta não só as violações aos interesses individuais inseridos no âmbito da relação jurídica processual, como também gera efeitos perniciosos no desenvolvimento social e econômico de uma nação.

Para melhor compreensão, trazemos a análise feita por Artur Cesar de Souza (2015) que, no que tange aos aspectos da celeridade processual, reporta aos relatórios anuais do Banco Mundial, para avaliar que a lentidão judiciária foi um dos principais freios do desenvolvimento produtivo na Itália, pois ela produz uma forte incerteza nas trocas comerciais e desencoraja os investidores nacionais e estrangeiros, representando um fortíssimo encolhimento em todos os outros indicadores internacionais ${ }^{2}$. Delimitando o conceito de duração razoável, Souza (2015) elenca os critérios fixados pelo Tribunal Europeu de Direitos Humanos, que consideram a natureza e circunstância do litigo, a complexidade e média geral dos litígios com o mesmo objeto, conduta do demandante e do órgão judicial e as consequências para os litigantes em razão da demora.

Assim, a taxa de congestionamento dos juizados especiais cíveis afeta a razoável duração do processo, o que significa um comprometimento da sua eficácia. Trazendo a análise feita no âmbito internacional para a realidade brasileira, Fernanda Estevão Picorelli (2015) destaca que o Conselho Nacional de Justiça denomina como taxa de congestionamento o

\footnotetext{
${ }^{2} \mathrm{O}$ autor ao reportar-se ao trabalho de Maurzio De Paolis, evidenciou que, em 01.01.2010, a Itália figurava em $5^{\circ}$ lugar, com 7.150 processos pendentes dentre os países com maior número de recursos promovidos perante a Corte Europeia de Direitos do Homem de Starburgo, perdendo apenas para Rússia, Turquia, Ucrânia e Romênia. Esses recursos apresentados àquela corte tinham duas grandes questões, sendo a principal a da excessiva duração dos processos. SOUZA, Artur Cesar de. Celeridade processual e a máxima razoabilidade no novo CPC (Aspectos positivos e negativos do art. $4^{\circ}$ do novo CPC). Revista de Processo. Vol. 246. Ano 40. São Paulo: RT, ago. 2015.
} 
montante apurado equivalente à soma dos casos novos e dos casos pendentes que aguardam o julgamento e o índice global. No que diz respeito à situação dos juizados especiais cíveis, recorre-se aos dados coletados por Ferraz (2015), referente ao ano de 2006, onde a média nacional, com ações finalizadas por composição, foi de 83 dias. Quando o processo teve a sentença cumprida voluntariamente pela parte vencida, direito do autor foi satisfeito em 193 dias, mas quando foi necessário adentrar a fase executória para a entrega do resultado prático pretendido, a espera total foi de 494 dias. Quando a sentença foi atacada por recurso e depois executada, o autor precisou aguardar 693 dias para receber o bem que foi objeto da ação.

Neste contexto, é necessário averiguar se o Poder Judiciário está adaptado para conferir a efetividade, pois não adianta assegurar o direito fixado em lei se a estrutura estatal não estiver adequada para um acesso qualitativo. Ao longo dos anos, os dados estatísticos indicaram um crescimento no número de demandas distribuídas e daquelas pendentes, o que tem trazido preocupação quanto à litigiosidade contida.

Este fenômeno, segundo Ferraz (2010) pode ser entendido como consequência gerada pela incapacidade do sistema de Justiça e, proporcionar à parte aquilo a que faz "jus". Neste caso, a parte interessada busca o acesso à justiça, mas não é atendida por falta de eficiência. Em algumas circunstâncias, a causa desta ineficiência é decorrente da morosidade processual que, para reduzir seus efeitos, dependeria de um controle dos atrasos, sejam estes inúteis e desnecessários ao funcionamento do sistema de justiça, mas não seria a única hipótese de deficiência.

Para um melhor entendimento do problema causado na estrutura do campo judiciário pela morosidade judiciária, recorre-se a divisão feita por Boaventura de Souza Santos (2015) para a avaliação da possível fonte do problema. A morosidade sistêmica deve ser compreendida como sendo aquela que decorre da sobrecarga de trabalho, do excesso de burocracia, positivismo e legalismo. Já por morosidade ativa, é possível entender como a decorrente dos obstáculos produzidos pelos próprios interessados no litígio, visando impedir a sequência normal dos procedimentos com vista ao desfecho do caso.

Trazendo estes conceitos para a análise do objeto desta pesquisa, em se tratando da eficiência das demandas no âmbito dos juizados especiais cíveis, é possível constatar que a demora processual é muito mais onerosa para as pessoas de baixa renda, pois elas se tornam vítimas dos custos dos processos do que para as demais classes sociais (FERRAZ, 2015). Não 
é forçoso reconhecer que, para aquelas, trata-se do único meio de acesso à justiça, pois é nele que há o menor dispêndio de dinheiro, pois não há adiantamento de custas, há assistência jurídica nos tribunais e não exige muitas despesas com deslocamentos ao fórum.

Nesta conclusão, pode ser constatado que não se trata apenas do volume de ações distribuídas nos juizados especiais cíveis que macula o direito fundamental a uma prestação num tempo razoável, existem outros fatores que foram apontados como comprometedores na estrutura do campo judiciário e com reflexos para a eficiência da tutela jurisdicional.

\section{ASPECTOS ESTRUTURAIS DOS JUIZADOS ESPECIAIS CÍVEIS}

No Brasil, a ideia de acesso à justiça começou a ser ampliada a partir da criação dos juizados especiais de pequenas causas. Estes juizados que foram regulamentados pela Lei Federal 7.244, de 7 de novembro de 1984, e, posteriormente, substituídos, com a vigência Lei Federal n. 9.099 de 26 de setembro de 1995, pelos juizados especiais cíveis. A hipótese trazida nesta pesquisa é averiguar a eficiência deste acesso à prestação jurisdicional nos dias atuais.

Por mais de duas décadas, os juizados especiais cíveis sofrem com as mazelas que são conhecidas dos processos de primeira instância, que é a desproporcionalidade entre o volume de ações distribuídas em relação à movimentação processual e cartorária. Para tanto, este trabalho se ocupa, neste tópico, de fazer uma análise do quantitativo de demandas distribuídas nos juizados especiais cíveis, com a delimitação geográfica ao Estado do Rio de Janeiro e especificamente nos juizados do Tribunal de Justiça desta unidade federativa.

Num segundo momento, a análise irá considerar o tempo estimado de tramitação das demandas nos juizados especiais a partir da fase processual, considerando ainda o acervo cartorário, os processos encerrados por conciliação e a estimativa do tempo morto. A terceira etapa será averiguar o quantitativo de servidores lotados e os juízes que estão vinculados a estes juizados. Para que este resultado possa ser aferido com mais solidez, a pesquisa irá recorrer aos dados estatísticos do Conselho Nacional de Justiça, para o ano de 2020, divulgados no Projeto Justiça em Números 2021.

Adentrando a terceira fase de análise dos dados, é necessário verificar o quadro de recursos humanos disponível para manejar o volume de trabalho dentro do campo judiciário, 
promovendo o resultado prático pretendido, mesmo diante de um elevado acervo processual. Neste parâmetro, o Poder Judiciário brasileiro tem um total de 1.217 juizados especiais cíveis, na esfera estadual e que corresponde a $0,2 \%$ do total da estrutura judiciária. O Conselho Nacional de Justiça classificou o Tribunal de Justiça do Estado do Rio de Janeiro como de grande porte, face ao quantitativo de habitantes atendidos pela estrutura.

É necessário inaugurar esta avaliação de dados estatísticos com a observação do tempo médio que uma demanda exige, desde a sua distribuição até a sua baixa. É importante destacar que $97,76 \%$ dos processos estão tramitando em meio virtual. No âmbito dos juizados especiais cíveis, um processo tramita por 1 ano e 9 meses, se o processo se tratar de uma execução extrajudicial, este tempo reduz para 1 ano e 7 meses. No caso de uma execução judicial, este tempo reduz para 1 ano e 6 meses. Quando a sentença e atacada por recurso, há o acréscimo de 1 ano e 2 meses, para o período em que o processo tramitará nas turmas recursais.

O tempo médio para a prolatação da sentença na fase de conhecimento é de dez meses, já na turma recursal é de seis meses para proferir o acórdão. Numa análise mais pontual, os juizados especiais cíveis ainda são meios eficazes de atendimento da parcela da sociedade que procura o Estado no intuito de dirimir um conflito de simples conflituosidade, porém não traduzem a celeridade que o indivíduo almeja, levando em conta que se trata de conflitos sociais de menor complexidade, o que não se efetiva ante o volume elevado de processos em tramitação.

A primeira consideração a ser feita é que, em sede de juizados, o maior lapso temporal se dá quando há recursos em tramitação nas turmas recursais.

O Conselho Nacional de Justiça apurou, no ano de 2020, que a taxa de congestionamento foi de $73 \%$. Sendo o índice de processos resolvidos por conciliação em fase de conhecimento de 13,3\%. Este índice quando avaliada a conciliação total, incluída a fase pré-processual reduz para 3,4\%. Não obstante, constata-se divergência quando a avaliação é feita pelos dados fornecidos pelo Tribunal de Justiça do Estado do Rio de Janeiro, com alteração no percentual de taxa de congestionamento nos juizados especiais cíveis que foi de $43,81 \%$ e de $20,56 \%$ nas turmas recursais.

Importa apresentar ainda o quadro de recursos humanos que está distribuído dentre as unidades judiciárias e que é responsável pela circulação da carga de trabalho. Neste viés, é 
possível contrastar que quanto maior for o campo analisado, maior será a carga de trabalho e maior o número de recursos humanos. O Conselho Nacional de Justiça contabilizou no quadro de recursos humanos do tribunal fluminense, no que tange ao quantitativo de servidores 12.980 ativos e 671 juízes. Deste montante, não há indicativo de quantos estejam vinculados efetivamente aos juizados especiais cíveis. No estado do Rio de Janeiro foram instalados 73 juizados especiais cíveis e 54 adjuntos totalizando 127 unidades em toda unidade federativa, com 5 turmas recursais cíveis e cabe ainda indicar que estão instalados 33 Centros Judiciários de Solução de Conflitos e Cidadania.

Tomando este quantitativo de pessoal, sobre a percepção de razoável duração do processo deve ainda conter a avaliação do tempo de tramitação de uma lide, para que se possa ponderar o segundo questionamento feito a respeito do tempo ideal para tramitação de uma demanda.

Os juizados especiais cíveis, outrora pensados para tornar o conceito de uma justiça mais célere uma realidade, não têm condições de serem tão otimizados na sistemática que é apontada pelas estatísticas do Conselho Nacional de Justiça e do Tribunal de Justiça do Estado do Rio de Janeiro. Esta posição é assumida a partir dos dados obtidos na estatística realizada pelo DGJUR/DEIGE/DICOL, departamentos do Tribunal de Justiça do Estado do Rio de Janeiro, ao identificar nos 127 juizados que, no ano de 2020, foram baixados 2.553.895 feitos. Não obstante, a quantidade perceptível de produtividade, há remanescente no acervo da primeira instância dos juizados especiais cíveis e o acervo de casos pendentes nos juizados, no mesmo período, é de 2.047.667 processos.

Outro tópico da análise estatística pelo DGJUR/DEIGE/DICOL, refere-se ao volume de processos baixados nas turmas recursais do Tribunal de Justiça do Estado do Rio de Janeiro, em 2020, foram 323.943 casos, com acervo pendente de 79.827 processos. Diante deste quadro, importa afirmar que o acervo remanescente ainda é alto, o que pode ser causa de descrédito da eficiência do acesso à justiça por meio dos juizados especiais cíveis. Desta forma, pode-se averiguar que o índice de atendimento à demanda nos juizados especiais cíveis é de $131,50 \%$, sendo na fase de execução de $11,69 \%$, enquanto que nas turmas recursais é de $100,55 \%$.

Por este demonstrativo aponta-se que a hipótese trazida no bojo do Projeto de Florença se desviou do seu objetivo, quando no Tribunal de Justiça do Estado do Rio de 
Janeiro, os juizados especiais cíveis não conferem à prestação jurisdicional uma entrega de tutela célere. De acordo com o relatório do Projeto de Florença, indica-se que os problemas decorrentes das sociedades contemporâneas precisam ser superados através de uma ruptura nas instituições jurídicas para tornar efetivos os direitos do cidadão comum. Com este relatório encaminhou-se diretrizes adotadas no sentido de garantir igualdade de armas às partes antagônicas, enfatiza-se neste artigo as causas que envolvem somas relativamente pequenas, capazes de serem submetidas aos juizados especiais cíveis.

Noutro giro, a solução dada pelo Tribunal para tornar ágil o trâmite processual é a criação de faixas reversíveis, a exemplo do que se dá na engenharia de trânsito, com a implementação políticas públicas para minimizar o quantitativo de processos paralisados pelo reduzido número de servidores. É possível aferir que o Índice de produtividade dos juízes nos juizados especiais cíveis do Tribunal de Justiça do Estado do Rio de Janeiro é de 4.219 sentenças na fase de conhecimento, 204 sentenças na fase de execução e 1.431 acórdãos nas turmas recursais.

Se por um lado, há a adoção da política pública judiciária de mutirões, onde um grupo de auxiliares e juízes se consolidam em deixar de fazer o atendimento de partes, estagiários e advogados em um dia específico da semana para agilizar as atividades internas. Em outro polo, a falta de serventuários é minimizada pela contratação de estagiários, estudantes dos cursos jurídicos com o desvio da função de aprendizado, criando assim a desvirtuação da função social do acadêmico em fase de desenvolvimento profissional. A solução para o volume de demandas tem sido pensada pelo Poder Judiciário com a implementação de termos de cooperação técnica e mutirões de conciliação onde todos estão determinados a apagar pequenos focos do incêndio, como meio de suprimir do volume de demandas de empresas de telefonia e bancos no âmbito dos juizados especiais cíveis.

No meio das já pautadas características do acesso à justiça, percebe-se claramente que não é só o consumidor que sofre com os transtornos decorrentes do serviço mal feito ou mal prestado, mas também o Estado que, com a ausência no exercício do múnus, torna uma ação para pacificação de um conflito social simples num tormento para a parte que menos recursos possui, a exemplo do homem comum.

Apesar das aparências nefastas, os juizados especiais cíveis ainda são meios eficazes de atendimento da parcela da sociedade que procura o Estado no intuito de dirimir um conflito 
de simples conflituosidade. Com uma estrutura procedimental mais singularizada poderá atingir o resultado pretendido num espaço de tempo razoável, mas ainda não tem a capacidade de trazer dentro do mesmo ano o resultado prático pretendido para as partes envolvidas.

É fato reconhecido, hoje, que os juizados especiais levam mais tempo para julgar do que quando foram instituídos, o que demanda paciência e perseverança, o que não é compatível com a duração razoável do processo, direito fundamental garantido pela Constituição da República. Aqui importante trazer a consideração o posicionamento de Aurélio Wander Bastos a despeito da importância do Poder Judiciário no contexto social e sua necessidade de abertura às novas violações que reclamam a proteção legal:

“(...) no quadro da crise política, o que o Poder Judiciário precisa é reconhecer os seus próprios limites e programas as suas reformulações, tendo em vista as suas tradicionais competências, os efeitos residuais dos fatos sociais novos, os fatos consuetudinários que necessitem de proteção legal, as próprias relações sociais juridicamente desprezadas, o envolvimento judicial nos conflitos em processo de complexificação e, especialmente, o seu papel nos conflitos de poderes".

Muito embora ainda tenha uma estrutura procedimental mais singularizada, o tempo de tramitação ainda compromete a eficácia da sua essência, pois a fase de execução exige cada vez mais paciência e perseverança, em linha oposta ao princípio da duração razoável do processo, evidenciado uma crise de natureza política no campo judiciário.

\section{CONSIDERAÇÕES FINAIS}

As contingências para a obtenção de uma prestação jurisdicional efetiva cruzam fronteiras que demandam muito mais que recursos materiais e estruturais para a sua concretização, este motivo é determinante para que o Tribunal de Justiça do Estado do Rio de 
Janeiro promova políticas públicas judiciárias para melhorar a realidade os juizados especiais cíveis, com a finalidade de entregar uma prestação jurisdicional efetiva com o custo de recursos menos elevado possível.

A preocupação do Conselho Nacional de Justiça, desde a sua criação, é obter meios de desenvolvimento para os métodos de resolução da crise da morosidade instalada do poder judiciário, almejando ampliar as de matrizes pelas quais se possam ofertar uma prestação jurisdicional mais célere é o que a doutrina tem inclinado a suscitar, sempre observando que a desigualdade existente se faz tanto por aspectos culturais, quanto por aspectos econômicos.

Buscar a diminuição dos obstáculos ao acesso à justiça é um dos fatores que levaram o Tribunal de Justiça do Estado do Rio de Janeiro a desenvolver indicativos de gestão estratégica para melhorar a redução de custos, facilitando ainda aqueles litigantes de baixo nível econômico e educacional, que também prejudica os autores individuais, já que, por este canal, outras formas de assistência jurídica são viabilizadas aos jurisdicionados.

Se pensar o debate da Justiça como meio de pacificação social, demarcar o termo é considerar que se trata de uma virtude de dar a cada um, o direito que lhe pertence, inserindo nesta perspectiva de entregar a Justiça, com a redução não só de custos ambientais, mas também de acessibilidade aos indivíduos ao desenvolvimento da prestação.

A avaliação do princípio da razoável duração do processo num ambiente digital traz à luz que a problemática do quadro de pessoal pertencente ao Poder Judiciário representa significativamente para a elevada taxa de congestionamento. Neste perfil, estão inseridos juízes, servidores do quadro efetivo, requisitados ou cedidos de outros órgãos, como também comissionados sem vínculo efetivo, mas também os trabalhadores auxiliares que contribuem para a estrutura da força do trabalho, como os terceirizados, estagiários, os juízes leigos, conciliadores e colaboradores voluntários. A estrutura do campo judiciário é composta no sentido de haver a melhoria dos indicadores de gestão de forma diligente, no que diz respeito ao planejamento estratégico traçado para atender os múltiplos segmentos de justiça.

É cabível considerar que os processos em fase de execução contribuem, em grande parte, para a manutenção do perfil de morosidade, pois não há satisfatividade da prestação jurisdicional. Esta situação promove impactos não só na taxa de congestionamento, como também na qualidade da tutela judicial, uma vez que descumpre preceito fundamental contido na Constituição. Este acervo na fase de execução pode ser traduzido como o esgotamento dos 
meios previstos em lei sem que houvesse a localização de patrimônio capaz de satisfazer o crédito, o que ainda retém o elevado número de feitos, como apontado.

Enquanto isto, o tempo de tramitação do processo continuará elevado, já que é contabilizado todo o lapso temporal existente entre a distribuição da ação e a baixa definitiva, apesar de, como início de postura de efetividade da prestação jurisdicional, haver redução do estoque diante do volume de casos novos. Pelo volume médio de ações, no ano de 2020, importa assinalar que a estrutura judiciária está em plena modernização para acompanhar as demandas sociojurídicas, recorrendo à utilização de processos judiciais eletrônicos, mas ainda encontra entraves à gestão estratégica do campo judiciário e, consequentemente, influenciando o resultado final de razoável duração do processo.

\section{REFERÊNCIAS}

BRASIL. Conselho Nacional de Justiça. Justiça em números. 2021. Disponível em https://www.cnj.jus.br/wp-content/uploads/2021/09/relatorio-justica-em-numeros2021-12.pdf. Acesso em 20.set.2021.

BRASIL. Lei Federal n. 7.244, de 7 de novembro de 1984. Dispõe sobre a criação e funcionamento do Juizado especial de pequenas causas. Disponível em http://www.planalto.gov.br/ccivil 03/LEIS/1980-1988/L7244.hmtm. Acesso em 27.set.2019.

BASTOS, Aurelio Wander. Conflitos sociais e limites do Poder Judiciário. $2^{\text {a }}$ edição revista e atualizada. Rio de Janeiro: Lúmen Júris. 2001.

CALAMANDREI, Piero. A crise da justiça. Tradução de Hiltomar Martins Oliveira. Belo Horizonte: Editora LÍDER, 2004.

CAPPELLETTI, Mauro. GARTH, Bryant. Acesso à justiça. Tradução e revisão Ellen Gracie Northfleet. Reimpressão. Porto Alegre: Sergio Antonio Fabris Editor. 1988.

CARNEIRO, Paulo César Pinheiro. Acesso à justiça: juizados especiais cíveis e ação civil pública: uma nova sistematização da teoria geral do processo. Rio de Janeiro: Forense, 2007. 
FERRAZ, Leslie Sherida. Juizados especiais cíveis e duração razoável do processo - Uma análise empírica. Revista de processo. Vol. 245. Ano 40. p. 523-547. São Paulo: RT, jul. 2015.

Acesso à justiça: uma análise dos juizados especiais cíveis no Brasil. Rio de Janeiro: FGV, 2010.

GRECO, Leonardo. Instituições de processo civil. Introdução do Direito Processual Civil. Volume I. 5a edição revista, atualizada e ampliada. Rio de Janeiro: Forense, 2015.

MARINONI, Luiz Guilherme; ARENHART, Sergio Cruz; MITIDIERO, Daniel. Novo curso de processo civil: tutela dos direitos mediante procedimento comum. Volume II. São Paulo: Revista dos Tribunais, 2015.

O novo processo civil. São Paulo: Revista dos Tribunais, 2015.

Novo código de processo civil comentado. São Paulo: Revista dos Tribunais, 2015.

PICORELli, Fernanda Estevão. A justiça e o paradigma da eficiência na contemporaneidade. Revista de Processo. Vol. 241. Ano 40. São Paulo: RT, mar. 2015. p. 439-461.

PINHO, Humberto Dalla Bernardina de. Direito Processual civil contemporâneo. Volume I: teoria geral do processo. $6^{\text {a }}$ edição. São Paulo: Saraiva, 2015.

RIO DE JANEIRO. Tribunal de Justiça do Estado do Rio de Janeiro. Indicadores Estratégicos. Disponível em https://portaltj.tjrj.jus.br/documents/10136/1243725/congestionamentoconhecimento.pdf/3eb8341f-e24a-4ea3-a575-10f8e4ca5959?version=1.8. Acesso em 21.setembro. 2021.

RIO DE JANEIRO. Tribunal de Justiça do Estado do Rio de Janeiro. TJERJ em Números. Disponível em https://portaltj.tjrj.jus.br/documents/10136/7912888/tjerj-emnu\%C2\%B4meros-jul2021-tela.pdf/6c178172-ce6f-aae2-c656-d82af60b4595?version=1.0..

Acesso em 21.setembro.2021.

SANTOS, Boaventura de Souza. Para uma revolução democrática da justiça. $3^{\text {a }}$ edição revista e ampliada. São Paulo: Cortez, 2007. 
SOUZA, Artur Cesar de. Celeridade processual e a máxima razoabilidade no novo CPC (Aspectos positivos e negativos do art. $4^{\circ}$ do novo CPC). Revista de Processo. Vol. 246. Ano 40. São Paulo: RT, ago. 2015. 